\title{
Digital Companies Facing the Challenges of Skill Adaptation: A Quantitative Analysis of the Uses of Training in France
}

\author{
By Jean-Marie Dubois* \\ Patrick Rousset
}

Digital companies operate in a highly competitive environment where rapid technological change is transforming the market, products and structures. To adapt to this competition, companies must generate rare skills and costly innovation creation processes. Rapid change requires a very strong internal dynamic of adaptation that can also be adapted to external collaborations. Knowledge management and cooperation is therefore a very strong challenge that requires transforming individual knowledge into collective knowledge, and academic knowledge into tacit knowledge. To achieve this objective, which concerns the high level of individual qualification, the transfer and operationality of knowledge, recruitment and training are at the core of a management strategy. Given the diversity of the challenges, companies use a wide range of training methods (formal, nonformal and informal) and integration practices of recruits into the collectives (mainly tutoring). All these practices are compatible with the collective's objectives of enhancing (internal and external) collaboration, maintaining operationality and acquiring rare knowledge. The French training and employee trajectory surveys (dispositif d'enquêtes sur les formations et itinéraires de salaries/Defis), which provides information on companies' internal organizations, recruitment and training methods, allows a very broad analysis of digital companies. They make it possible both to reflect the importance of these practices in relation to the rest of the economy and to test our hypothesis of the impact of the innovation factor on recruitment and training methods. Finally, this impact study is completed by contextual factors such as market territoriality, growth and integration into networks or groups of companies.

Keywords: Digital, Innovation, Knowledge, Recruitment, Training.

\section{Introduction}

French digital companies are experiencing strong growth, both in terms of capitalization and turnover, which has spotlighted training needs and human resources more generally. In this highly competitive sector, wealth creation and therefore growth are strongly linked to innovation. The search for innovation is often based on the pooling of new, high-quality knowledge, which is fuelled by two complementary dynamics. On the one hand, companies need to recruit highly qualified operational staff. On the other hand, the various forms of vocational training appear to provide solutions to enable companies to remain competitive

\footnotetext{
*Junior Researcher, French Centre for Research on Education, Training and Employment (Céreq), France.

${ }^{\ddagger}$ Senior Researcher, French Centre for Research on Education, Training and Employment (Céreq), France.
} 
and at the cutting edge of innovation. Once new knowledge is acquired, efficiency depends on the way it is embedded in the cooperative organization. Internal skill adaptation practices could benefit from a matching dynamic between companies and public actors in training.

We propose to draw on the results of the French training and employee trajectory surveys (dispositif d'enquêtes sur les formations et itinéraires de salaries/ Defis) in order to investigate training and recruitment practices in the digital sector. The data illustrate the willingness of these companies to capitalize on all the processes of skill adaptation: from recruitment policies focusing on qualification level and subject to increasingly strong competition to the various continuing training policies that focus on adaptation to the workplace.

The aim of this paper is to identify the knowledge management practices by measuring the significance of the indicator "innovation" and to verify the corroboration between the results and the assumption that human resources are organized in a way consistent with a knowledge-based strategy. The main results are that innovation affects a set of characteristics such as the levels of non-formal and informal training and the objectives of recruitment. Moreover, the integration and tutoring practices deployed as part of the recruitment process are indicators of knowledge conversion practices in which initial explicit academic knowledge is transformed into tacit and productive knowledge. The inclusion of tutoring functions among the job characteristics provides a foundation for the use of social practices in innovation. As a supplement to these findings, employees confirm the companies' point of view. Finally, the consistency between these indicators supports the hypothesis of a corporate strategy that offers a competitive advantage in innovation, as knowledge management theory would suggest.

The article is structured as follows. The first part details the review of literature and shows the impact of innovation in different contexts such as technological change, competitive environments and knowledge management. In the second part, we present the data coming from the Defis survey and the methodology used for our study. In the third part, based on the results of the survey, we analyse the context in which digital companies operate. In the two final parts, we give an empirical account of the role played by different factors, such as the innovation process, on recruitment objectives and different forms of training opportunities. We put forward those results in a human resources perspective, as a multidimensional process related not only to capability for learning and training but also including capability for maintaining companies' competitiveness.

\section{Literature Review and Positioning of our Study}

The aim of our study is the management in digital companies and the impact of innovation, focusing the recruitment and training components. The three main requirements are firstly the collaborative internal/external organization in a high competitive environment, secondly the fitted collective knowledge and the conversion of individuals knowledge to tacit knowledge in innovation, (cf. respectively next two subsections). Subsection "Pressures and barriers for digital 
companies" purposes is the question of the radius of action and barriers of the companies action when being an actor in the development of knowledge in their own territorial environment (e.g. in the region in which they are located) provides firms some benefit (Deltour and Lethiais, 2014).

The background of the study is very large because the evolution of technology is very rapid and innovation concerns the nature of products, market and environment structures, communication in networks and capitalization of knowledge. The literature indicates how companies organize their innovation practices differently depending on their sector of activity (Mongo, 2013; Rogers, 2004). For example, the nature of innovation is different in manufacturing (Gallouj, 2002) and services (Cordelier, 2011) which includes the very specific digital sector. Another specifies the impact of technology on the organization of internal and external collaboration (Banker et al., 2006; De Meyer, 1991) and on management structures (Banker et al., 2006). New technologies are also perceived as a vector for the capitalization of knowledge for companies in R\&D (Pavlou and El Sawy, 2006).

\section{Innovation in a Highly Competitive Environment}

Teece (1998) refocuses the framework of competition in innovation on companies' internal organizational structures and managerial processes. The proposed approach to management, the so-called dynamic capabilities approach, integrates rapid environment change and innovation requirements in a context of high competition. It divides the strategic problems into game theory approaches to rival companies and company-specific assets, which is our main focus here. They are defined as resources that are difficult to imitate, primarily because they contain tacit knowledge, in line with resources in the resource-based approach (Barney and Clark, 2007; Nelson and Winter, 1982; Kogut and Zander, 1992; Nonaka and Von Krogh, 2009).

For being competitive, the product has to be proprietary and know-how must be easy to replicate for the companies and costly to imitate for the contestants (Rogers, 2004). Barney and Clark (2007) define the quality criteria that assess the potential for competitiveness as valuable, rare, imitable resources and organisation. The dynamic capabilities approach integrates the ability of companies to build or reconfigure internal and external competencies depending on rapid environment change. Consequently, competencies and knowledge management are in the core of the companies' competitive level.

\section{Collective Knowledge and the Organization of Human Resources}

Knowledge management is not an easy task when knowledge belongs to individuals. Thus, the competitive advantages of companies depend mainly in the sharing of individuals' knowledge within an organization or social community that may be partially external. Implicit rules between group members define social practices that shape collaborations. Consequently, knowledge management must be socially constructed through the organization of human resources. Knockdown 
is central to social organization since it is an essential element to be accepted in a community, a product of exchange within the collective and a constituent of the value created.

In the "knowledge-based management", knowledge has a central position in strategic management (Spender and Grant, 1996; Kogut and Zander, 1992; Nelson and Winter, 1982; Boisot, 1998). Kogut and Zander (1992) present knowledge management as an element at the very core of firms' organization of human resources: "... why [do] companies exist? ... Companies exist because they provide a social community of voluntarist actions structured by principles that are not limited to individuals" or "It is important to underline the presumption that the knowledge of the company must be understood as socially constructed or, more simply stated as resting in the organization of human resources". This organization facilitates the transfer of social knowledge as well as the creation of new knowledge or learning. A distinction is made between information and knowhow: information is defined as the knowledge that can be transmitted without loss of integrity and know-how refers to the accumulation of learned and acquired knowledge.

In knowledge management theory, "Organizational knowledge creation is the process of making available and amplifying knowledge created by individuals as well as crystallizing and connecting it to an organization's knowledge system" (Nonaka and Von Krogh, 2009). They develop the concept of knowledge conversion: "knowledge is the capacity to act". The conversion from academic to tacit knowledge is a principal factor in efficiency in innovation and the relationship between the two forms of knowledge is crucial to corporate knowledge organization.

\section{Pressures and Barriers for Digital Companies}

This section proposes a background of a critic and reflexive content about the pressures and possible barriers that innovation in the digital sector poses for both employees and companies. It focuses on the ecosystem and territorial influence.

As already specify, social knowledge practices can be extended to network structures providing some benefit but also some replicability and imitation risks that increase in a collaboration context. Considering the mutual influence of the company and its ecosystem, the company's performance depends on the level of development of the ecosystem and the territory, which define the limits of the potential of a proactive strategy (Gertler et al., 2000; Shaeffer and Matt, 2016). Literature highlights the influence - on the potential of companies - of the presence of public institutes, large companies, research institutes, etc. (Simon, 2009; Cave, 2000).

Finally, in this paper, the management of internal and external organizational skills construction refers to knowledge management in accordance with the resource-based approach. The study focuses mainly on the recruitment and training components resting on companies answer in the DEFIS survey. By the way, the field is limited to companies' internal and external actions and completed 
with individual answers. The territory activity is a dimension to be considered for future assessments.

\section{The Data and the Methodology of our Study}

\section{The Data: The DEFIS Surveys and the Cluster of Digital Companies}

In this study, the data are gathered by extracting information on digital companies from the French training and employee trajectory surveys (Dispositif d'Enquêtes sur les Formations et Itinéraires des Salariés/DEFIS). These surveys, initiated by the National Council for the Evaluation of Vocational Training (Conseil national d'évaluations de la formation professionnelle/CNEFP), are designed by Céreq. Their objective is to compare the training courses attended by employees and their career trajectories. A total of 3,379 companies representing private sector companies with 10 or more employees were surveyed in 2015 as part of the 'companies' strand of the survey. A panel of 16,000 individuals employed in these companies in December 2013 will be surveyed annually over a period of 5 years (from 2015 to 2019) to constitute the employees strand. The companies strand aims to gather detailed information on the context (human resources policy, continuing training policy, work organization, structural characteristics, etc.) in which employees are (or are not) trained.

The cluster of digital companies is a sample of 281 companies in the digital sector with 10 or more employees taken from the survey as a whole. The companies in the digital sector have signed the corresponding collective agreement and also come under the associated official referencing. The sector encompasses a number of sub-sectors with certain specific job characteristics; they include the digital, engineering, audit and consultancy and events management industries. Moreover, public actors tasked with the collection of training levies are linked to the sector and their representatives are connected to the relevant employers' federations. According to the Joint Occupations and Skills Observatory for the Digital, Engineering, Audit, Consultancy and Events Management Sectors, the digital sector comprises 58,150 companies with 765,350 employees, more than $50 \%$ of whom have managerial or executive (cadre) status (OPIIEC, 2017). More importantly for this study, all these companies operate within an environment characterized by innovation, competitive markets and network structures.

\section{The Methodology of our Study}

In the one hand, the methodology aims to validate the hypothesis concerning the digital companies' environment: strong growth, rapid technology change and high competition, all linked with innovation. We have insisted on the variation of the modes of adaptation according to whether they are part of the internal organization or collaboration with its environment. We have chosen to focus the study on the digital sector, which is very homogeneous from the point of view of factors. In particular, the innovation factor has the same meaning for the whole 
sector (which is not the case for the whole economy). In our study, we define innovative companies as those that declare they introduced new technologies or developed a new product or service between 2012 and 2015; such companies represent two thirds of all digital companies.

In the other hand, we developed two logistic regression models to identify the main factors, notably the innovation process, influencing recruitment and training policies according to knowledge management. We took the following five aspects into account: (1) the presence of innovation, (2) the increase of competition, (3) the companies' (good) economic health, (4) their involvement in a group/network of companies and (5) their presence in an international market. Because our results are "other things being equal", we also controlled the structure of these companies: the size, the sector, and the share of executives. The management is expected to be in line with an objective of a high collective and tacit knowledge.

\section{Digital Context: Innovation, Competitive Market and Network Structures}

\section{Innovation and Growth, Two Interconnected Structural Factors}

Innovation is the core activity for a large number of digital companies. No fewer than 53\% of them developed a new product or service between 2012 and 2015 compared to an average for all sectors of 38\%; $40 \%$ of them introduced new technologies or processes, compared to $35 \%$ on average (see Figure 1).

\section{Figure 1. Innovation in Digital Companies (\%)}

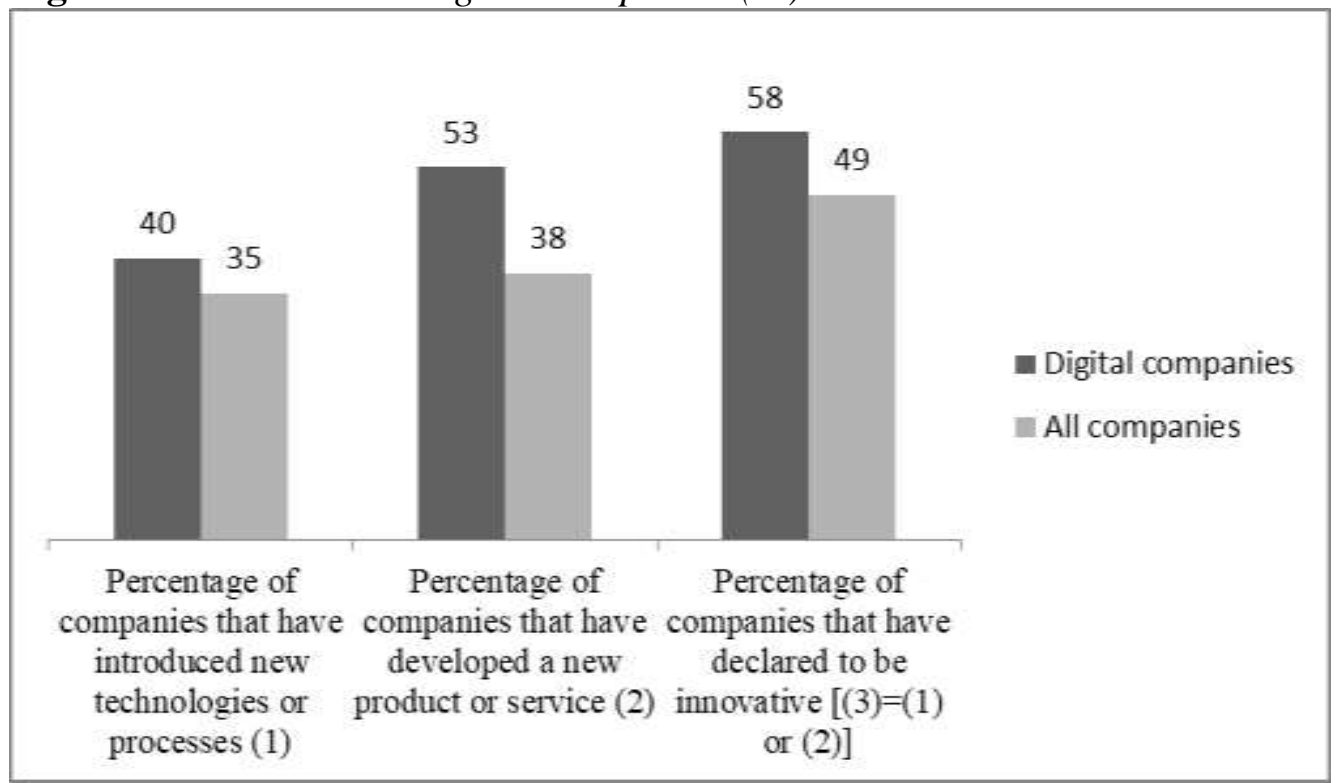

Source: CNEFP-Céreq, DEFIS companies strand, 2015.

Scope: companies with 10 or more employees at $31^{\text {th }}$ December 2014.

Reading Note: $58 \%$ of digital companies declared themselves to be innovative between 2012 and 2015. 
Digital companies benefit from the economic dynamics of their industry. Indeed, $27 \%$ of them saw the market corresponding to their main activity increase between 2012 and 2015 (compared with 18\% on average for all sectors). This relatively good performance particularly benefits small and medium-sized companies (36\% of companies in the sector have between 10 and 19 employees). Moreover, the share of companies in the sector that have seen their turnover rise is much higher than in the rest of the economy (51\% vs. $36 \%)$, while the share of those that have seen turnover fall is considerably smaller (21\% vs. $29 \%)$. This financial growth is reflected in the fact that $47 \%$ of these companies have seen an increase in the size of their workforce, which is characteristic of their strong responsiveness to the market. The survey requests companies about changes between 2012 and 2015, or since their creation (if it is after 2012) but ignores those that did not survive in 2015. Thus, our study concerns only surviving companies in 2015.

Digital companies use their economic growth to increase their potential to produce the innovations necessary to maintain their competitiveness and therefore their survival (Petrariu et al., 2013). Their strategy centred on innovation is also the main driver of these companies' economic dynamic, creating a virtuous circle around them (Coad and Rao, 2008).

\section{A Globalized Environment Fostering Cooperation between Actors}

The proliferation of creation spaces leads digital companies - especially the most innovative - to open up to others. This tendency is facilitated by the dematerialization of interactions made possible by digitalization. More than one third of the innovative digital companies are members of a business leaders' organization or members of associations, clubs or think tanks of HRDs or entrepreneurs (compared to less than one quarter of the non-innovative companies). These companies are therefore totally interconnected within an ecosystem in which new partnerships and alliances are constantly being forged with customers, suppliers and competitors (Ghoshal et al., 1992), the objective always being to accelerate innovation processes and reduce the time to market (CIGREF, 2014). This ecosystem is very extensive, with a multiplicity of actors: GAFAM, to which must be added BATX ${ }^{1}$, large companies, start-ups, innovative SMEs, selfemployed entrepreneurs, etc.

Digitalization enables them to expand their area of operation, which is more national, even international, and less local than average across the economy as a whole. Indeed, more than half of innovative digital companies say they operate in the international market (compared to one third of the non-innovative companies). To meet the demands of these very diverse markets, innovative digital companies have developed a greater ability than other companies to differentiate their customers or partners. Indeed, nearly half of them experienced changes in relations with partners or principals, compared to one quarter of their non-innovative counterparts.

${ }^{1}$ Google Apple Facebook Amazon Microsoft (GAFAM) and Baidu Alibaba Tencent Xiaomi (BATX). 
As previously shown, innovative digital companies are stakeholders in a market that is growing financially and in terms of the numbers employed. This situation is conducive to a recruitment and training policy where the call for young entrants and their integration is an issue to feed the job offer. The quality of methods employed can, in this context, reflect a strategy of adaptation to the requirements of innovation through the renewal of skills and knowledge.

\section{Targeted Recruitments and Integration Policies}

In a context of growth, in which financial constraints are lower, investments highlight the strategies companies adopt in order to improve performance, increase productive capacity and promote technological, organizational and management processes. Hence recruitment and training appear to be two of the main effective ways to achieve these objectives internally.

In this section, we will examine the objectives associated with recruitment policies in these companies, for example the profiles of the employees sought (young vs experienced) and the role played by the factor "innovation" in these choices. Given the difficulties companies experience in "attracting" certain profiles, we will detail all the means used by companies to manage job demand, whether by influencing the content of initial training, recruiting during the academic year or retaining trainees.

\section{Recruitment Prioritizing High Qualifications in Line with a Search for Excellence}

From 2010, employment has known moderate growth, driven by economic activity and the enrichment of job growth made possible by measures to reduce labor costs. ${ }^{2}$ The digital sector is one that contributes the most to job creation. According to the European Commission, growth prospects are estimated at $2 \%$ per year on average by 2020 (European Commission, 2014). The workforce has increased in line with the increase in production rather than undergone renewal. Indeed, more than three quarters of innovative digital companies stated that, between 2012 and 2015, they had recruited in order to meet a need to increase their productive capacity. Faced with such needs, all recruitment methods are widely used: professional networks, websites, educational establishments, service providers, etc.

Nevertheless, nearly $80 \%$ of innovative digital companies report difficulties recruiting for skilled jobs (compared to 59\% of the non-innovative). A French interdepartmental report on training needs and supplies in the digital professions published in February 2016 mentions three main recruitment difficulties (Ministry de l'Economie et des Finances, 2016). On the one hand, the digital industry comprises a family of diversified, specialized and rapidly changing occupations (experience often reaches its limit value after only a few years). On the other hand, companies often favour recruitment over their own technologies, which do not always meet ad hoc applications. Finally, it should be pointed out that companies

${ }^{2}$ Insee, 2017. 
include their recruitment in a very short-term business development plan based on the client and its IT tools, i.e. they operate in a more responsive framework than a traditional human resources policy.

In this context of shortages of experienced employees in the labour market, these companies are turning more and more to less costly young graduates with no experience and very characteristic profiles: namely those with 5 years of higher education or graduates of engineering schools or universities specialized in IT (OPIIEC, 2017). Almost two thirds of the innovative digital companies that recruited at least one employee between 2012 and 2015 did so in order to acquire new qualifications or skills (compared with one quarter of the non-innovative). This result confirms our hypothesis of a recruitment strategy oriented towards high qualifications that is consistent with a search for excellence driven by individuals.

A logistic regression model was developed to highlight significant links between companies' objectives when they recruit and certain structural factors (see Table 1). The first finding is that the very significant impact of innovation on the quality of recruitment is validated, particularly when the objective is to acquire new qualifications or skills. Companies are thus significantly more likely to pursue this objective when they declare themselves to be innovative. In contrast, the second observation is the importance of the economic health of companies when they seek to adapt the size of their workforce to the economic situation by increasing their productive capacity. The final observation is the significance of belonging to a group when companies aim only to replace employees who have left. Internal mobility is thus probably encouraged within the same group, which stimulates skill adaptation.

This is confirmed by the declarations of the employees still working in these companies in 2015 (631 employees who worked in an innovative digital company in December 2013 - see above). While only one quarter of these employees declared in 2015 that they wanted to change their job or occupation in the next 5 years, almost half wanted to find another job or change companies, which shows that they are happy to work in this sector of activity but are rather mobile and willing constantly to take up new challenges and develop their careers. Consequently, these companies need to take into consideration the needs, aspirations and values of their employees if they want them to stay motivated and committed to the same objectives (Lambert et al., 2012). 
Table 1. Logistic Model Evaluating the Probability that a Company Pursues Certain Objectives in Recruiting New Employees

\begin{tabular}{|c|c|c|c|c|c|}
\hline \multirow[t]{3}{*}{ 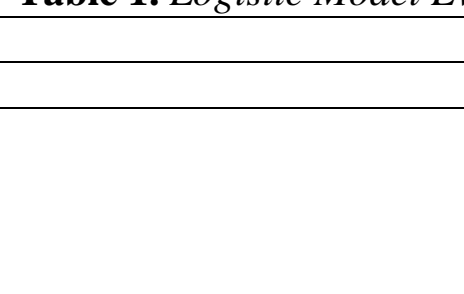 } & \multirow[t]{3}{*}{ 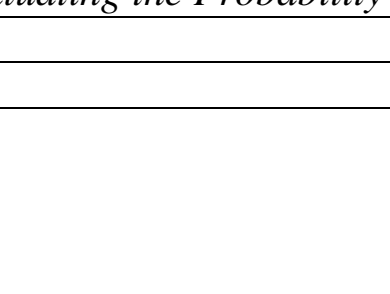 } & \multicolumn{4}{|c|}{ Variables to explain } \\
\hline & & \multicolumn{4}{|c|}{ (when they recruit) probability that the company aims to... } \\
\hline & & $\begin{array}{l}\text { The replacement of } \\
\text { employees who have left }\end{array}$ & $\begin{array}{l}\text { The increase in } \\
\text { productive capacity } \\
\text { (increase in staff) }\end{array}$ & $\begin{array}{l}\text { the acquisition of new } \\
\text { qualifications or skills }\end{array}$ & $\begin{array}{l}\text { The increase of } \\
\text { supervision }\end{array}$ \\
\hline \multicolumn{6}{|l|}{ Control variables } \\
\hline \multirow{3}{*}{ Size of the company } & $\begin{array}{c}\text { From } 10 \text { to } 49 \\
\text { employees }\end{array}$ & ref & Ref & ref & ref \\
\hline & $\begin{array}{l}\text { From } 50 \text { to } 249 \\
\text { employees }\end{array}$ & 0.3382 & -0.0189 & $0.6707 *$ & 0.1107 \\
\hline & 250 employees and more & $1.2738 * *$ & 0.3900 & 0.7514* & $0.8403 * *$ \\
\hline \multirow{4}{*}{ Sector of the companies } & Digital & Ref & Ref & Ref & Ref \\
\hline & Engineering & -0.0364 & 0.0585 & -0.0763 & -0.4414 \\
\hline & Events & 0.5573 & $-1.4737 * * *$ & -0.5825 & $-1.2719 * *$ \\
\hline & Audit & -0.0133 & -0.6852 & -0.1155 & -0.5430 \\
\hline \multirow{3}{*}{ Percentage of executives } & Less then $1 / 3$ & Ref & Ref & Ref & Ref \\
\hline & Between $1 / 3$ and $2 / 3$ & -0.0960 & 0.0390 & 0.5554 & 0.1433 \\
\hline & More than $2 / 3$ & -0.9197 & $1.0180 *$ & $1.0888 * *$ & -0.0520 \\
\hline \multicolumn{6}{|l|}{ Variables explicatives } \\
\hline \multirow{2}{*}{$\begin{array}{l}\text { The company has been } \\
\text { innovative over the past } 3 \\
\text { years }\end{array}$} & Yes & 0.5400 & -0.0109 & $1.2816 * * *$ & 0.3200 \\
\hline & No & Ref & Ref & Ref & Ref \\
\hline \multirow{2}{*}{$\begin{array}{l}\text { The company has } \\
\text { experienced increased } \\
\text { competition over the past } \\
\text { three years }\end{array}$} & Yes & 0.1473 & 0.1220 & $0.5422 *$ & -0.2539 \\
\hline & No & Ref & Ref & Ref & Ref \\
\hline \multirow{2}{*}{$\begin{array}{l}\text { The company operates on the } \\
\text { international market }\end{array}$} & Yes & -0.1383 & -0.2496 & 0.3405 & 0.2668 \\
\hline & No & Ref & Ref & Ref & Ref \\
\hline
\end{tabular}




\begin{tabular}{|c|c|c|c|c|c|}
\hline \multirow{2}{*}{$\begin{array}{l}\text { The company belongs to a } \\
\text { group/network }\end{array}$} & Yes & $0.6550 *$ & -0.1411 & 0.0891 & -0.1398 \\
\hline & $\mathrm{No}$ & Ref & Ref & Ref & Ref \\
\hline \multirow{2}{*}{$\begin{array}{l}\text { The company is in good } \\
\text { economic health }\end{array}$} & Yes & -0.0509 & $0.9061 * * *$ & -0.1151 & 0.0246 \\
\hline & No & ref & ref & ref & ref \\
\hline
\end{tabular}

Source: CNEFP-Céreq, DEFIS companies strand, 2015

Scope: Recruiting digital companies with 10 or more employees as at $31^{\text {th }}$ December 2014.

(ns: non-significant, $*=$ significant at $10 \%$, $* *=$ significant at $5 \%, * * *=$ significant at $1 \%$ ).

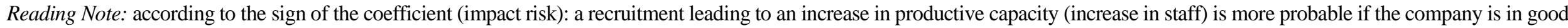

economic health, all other things being statistically equal, taking into account the profile adopted as a reference. 


\section{Companies Active in the Initial Training - Integration Link}

As indicated in the previous section, recruitment oriented towards high qualifications is not merely opportunism on the part of companies seeking to benefit from a favourable market. On the contrary, there are company practices which show that they seek to shape initial training in order to produce profiles in line with their expectations (Goshal et al., 1992). The recruitment policy is also similar to a strategy of early recruitment of young people in order to stabilize them as early as possible within these companies. Thus according to the results of the DEFIS survey, when they recruit new employees, half of innovative digital companies go directly to educational institutions such as prestigious universities (compared to one quarter of the non-innovative companies).

Individually or through the sector itself, innovative digital companies also take part in training courses in the form of conferences or seminars; they are involved in the boards of directors of these institutions and participate in developing the National Directory of Professional Qualifications (RNCP), etc. Their objective is to improve the content of qualifications and make them more adaptable to demand. Thus the renewal of skills through recruitment depends on the ability of schools and universities to supply the labour market with the right number of suitably qualified young people in terms of quality and number as well as on the ability of companies to make them known and attract new employees (Conseil d'Orientation pour l'emploi, 2017).

\section{A Policy of Integrating Incoming Employees through the Acquisition of Company Knowledge}

Digital companies are very satisfied with the qualifications of young recruits. Indeed, when they recruit, nearly three quarters of the innovative digital companies declare that all or almost all of new employees already had the appropriate qualifications and skills. Similarly, according to half of innovative digital companies, employees' skills are mainly acquired in the course of their work and, at the same time, one third declares that these skills were acquired before they were hired. Their efforts to improve employees' operationality through involvement in the education/training process prior to recruitment appear to be all the more notable since they are very satisfied with the skills acquired in initial training.

This confirms our hypothesis that the integration of young recruits does not correspond to a catch-up in level but to a concern for integration into work groups. Once this objective has been achieved, the young person will be able to benefit from the company's knowledge, collaborate in innovation processes and also bring his or her own knowledge to the group. 


\section{Continuing Training Practices in line with Collective Challenges but around Individual Skills Acquisition Dynamics}

Companies' investment in the acquisition of new skills through the recruitment of new employees with specific profiles is extended by increased use of continuing training to update them. After all, the level of qualification does not necessarily guarantee spontaneous adaptation to changes in work and to the market in which these companies operate. In addition to formal training leading to degrees or diplomas, there is so-called non-formal training that does not lead to a qualification but aims rather to enable individuals to acquire a specific, widely disseminated skill. Informal training is based more on individual initiatives and is more suited to delivering high-level content that is not widely disseminated (Fournier et al., 2017).

Until 2014, all companies were required to pay a percentage of their payroll in respect of continuing training of employees. If $30 \%$ do not use or very little of these funds to train their own employees (Devriès and Lê, 2015), $40 \%$ of companies spend more than of this minimum, such as digital companies that make use of continuing training in very intense and diverse ways. This reveals a search for excellence that is a source of innovation creation and a desire to master knowledge collectively.

\section{The Use of All Training Methods}

The skills required by employees working in digital are constantly evolving in order to adapt to the multiple consequences of digitalization, new needs expressed by customers, and the development of the activity. Thus continuing training is a crucial support for employees faced with constant change, especially in the innovative companies. It is therefore not surprising to observe that, for $43 \%$ of the innovative digital companies that organized continuing training for their employees in 2014, this is the main objective declared in the DEFIS survey (compared with just one quarter of the non-innovative companies). Usually, companies providing training fund it mainly in order to meet statutory requirements, especially among the smaller ones and in certain sectors with high levels of training provision: transport and construction industries (Dubois et al., 2016).

If the intensive search for new knowledge must result in the large-scale provision of continuing training, it is the diversity of training methods that reflects company policies aimed at ensuring the cohesion of the acquired skills. While training courses and training in the workplace remain the most popular training methods for all companies, the use of other non-formal training methods is more widespread in innovative digital companies. Thus $69 \%$ of them had at least one employee who attended a conference or seminar (compared to $33 \%$ of the noninnovative companies), $51 \%$ had at least one who undertook a self-training course (vs. $22 \%$ ) and $37 \%$ had at least one who completed an e-learning course (vs. 17\%). This strategy is justified by the profile of employees with high levels of education that are learning to master IT tools and being initiated into a collaborative culture. 
Table 2. Logistic Model Evaluating the Probability that a Company Uses Certain Continuing Training Methods

\begin{tabular}{|c|c|c|c|c|c|c|}
\hline & & & & Variables to explain & & \\
\hline & & & Probability & some employees have foll & in 2014 . & \\
\hline & & Training courses & $\begin{array}{l}\text { Training in work } \\
\text { situation }\end{array}$ & $\begin{array}{l}\text { Conferences or seminars } \\
\text { with the aim of learning }\end{array}$ & Self training & e-learning \\
\hline Control variables & & & & & & \\
\hline & $\begin{array}{l}\text { From } 10 \text { to } 49 \\
\text { employees }\end{array}$ & ref & ref & ref & ref & ref \\
\hline Size of the company & $\begin{array}{c}\text { From } 50 \text { to } 249 \\
\text { employees }\end{array}$ & 0.7239* & 0.4272 & $0.6610 * *$ & 0.5836* & $1.1156 * * *$ \\
\hline & $\begin{array}{c}250 \text { employees and } \\
\text { more }\end{array}$ & $1.3374 * *$ & 0.0102 & $1.3094 * * *$ & $1.1173^{* * * *}$ & $1.5855 * * *$ \\
\hline & Digital & Ref & Ref & Ref & Ref & Ref \\
\hline Sector of the companies & Engineering & -0.1696 & 0.1028 & 0.1278 & -0.6063 & -0.5636 \\
\hline sector or tile coumpantes & Events & -0.0666 & -0.2674 & -0.0493 & $-1.6099 * * *$ & -0.4764 \\
\hline & Audit & $-0.8674 *$ & -0.5287 & -0.0622 & $-1.2235 * * *$ & -0.5027 \\
\hline & Less then $1 / 3$ & Ref & Ref & Ref & Ref & Ref \\
\hline Percentage of executives & Between $1 / 3$ and $2 / 3$ & 0.6693 & $-1.0004 * * *$ & 0.2297 & 0.1901 & $0.6415 *$ \\
\hline & More than $2 / 3$ & 0.3898 & -0.3454 & $1.2280 * * *$ & 0.2284 & 0.2993 \\
\hline Explicative variables & & & & & & \\
\hline The company has been & Yes & $1.4912 * *$ & 1.1499* & $1.6084 * *$ & 0.1010 & 0.1820 \\
\hline $\begin{array}{l}\text { recruited over the past } 3 \\
\text { years }\end{array}$ & No & Ref & Ref & Ref & Ref & Ref \\
\hline The company has been & Yes & $1.1686 * * *$ & $0.5898 * *$ & $1.0866 * * *$ & $0.5854 * *$ & $0.8157^{* * *}$ \\
\hline $\begin{array}{l}\text { innovative over the past } 3 \\
\text { years }\end{array}$ & No & Ref & Ref & Ref & Ref & Ref \\
\hline The company has & Yes & -0.3216 & $0.5943 * *$ & 0.2020 & $0.5894 * *$ & 0.3439 \\
\hline $\begin{array}{l}\text { competition over the past } \\
\text { three years }\end{array}$ & No & Ref & $\operatorname{Ref}$ & Ref & Ref & Ref \\
\hline The company operates on & Yes & $0.6951 * *$ & 0.1738 & 0.1755 & 0.2805 & $1.1383 * * *$ \\
\hline the international market & No & Ref & Ref & Ref & Ref & Ref \\
\hline
\end{tabular}




\begin{tabular}{|c|c|c|c|c|c|c|}
\hline \multirow{2}{*}{$\begin{array}{l}\text { The company belongs to a } \\
\text { group/network }\end{array}$} & Yes & 0.3571 & 0.1318 & 0.5433* & 0.2365 & 0.2518 \\
\hline & No & Ref & Ref & Ref & Ref & Ref \\
\hline \multirow{2}{*}{$\begin{array}{l}\text { The company is in good } \\
\text { economic health }\end{array}$} & Yes & -0.5589 & 0.2268 & -0.1031 & 0.1991 & -0.0206 \\
\hline & $\mathrm{No}$ & ref & ref & ref & ref & ref \\
\hline
\end{tabular}

economic health

Scope: Digital companies with 10 or more employees as at 31th December 2014.

(ns: non-significant, $*=$ significant at $10 \%, * *=$ significant at $5 \%, * * *=$ significant at $1 \%$ ).

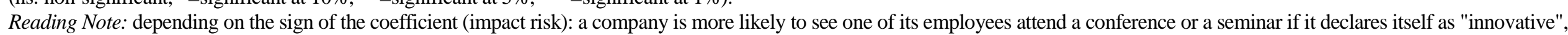

all other things being statistically equal, taking into account the profile adopted as a reference. 
A logistic regression model was developed in order to identify the factors that could influence the likelihood of a digital company using different training methods (see Table 2). Among these factors, "The company has recruited over the last 3 years" tests whether training policies tend to be part of a broader human resources policy that includes recruitment. The other factors are the same as those used in the previous chapter and refer to sectoral structures and economic opportunity. The first observation is the very significant influence of innovation on the diversity of forms of training compatible with a search for excellence. Thus employees in digital companies are more likely to have attended conferences or seminars or undertaken e-learning training or self-training when the companies declare themselves as innovative. Secondly, an intensification of competition seems to push companies into providing training internally (self-training or training in the work situation), which is consistent with the transmission of knowhow between colleagues and other results. Thirdly, good economic health does not have an impact on the use of training. While there is a strong link between innovation and growth within these companies, growth without innovation is not accompanied by investment in knowledge acquisition or renewal. A fourth observation is the importance of the target market in determining the content of the training policy, with the internationalization of a company's market greatly influencing its use of e-learning. The final observation is the significance of belonging to a group when companies declare that their employees have attended conferences or seminars. This factor shows the impact of work organizations on knowledge sharing, since collaboration and cooperation are at the core of these companies' strategy.

Training Planning as an Institutional Link between Training Practices and Business Strategy

Four fifths of the innovative digital companies analyse their employees' skills or qualification needs (compared with 59\% of the non-innovative companies), whether during formal evaluation interviews or during more informal exchanges. They therefore attach great importance to taking into account the skills that employees acquire in their work. Moreover, as the DEFIS survey shows, the latter are more involved in decision-making processes. All these factors encourage them to develop their skills. As stated in the Mettling report published in 2015, "the study of digital native companies testifies to a more agile work organization, structured in project mode, more open to an ecosystem, much more efficient in particular to disseminate innovations". As a result, work organization is undergoing transformations likely to foster learning opportunities (Mettling, 2015; Van der Heijden, 2003; Kraimer et al., 2011; Doran et al., 2012) whereas previous forms - notably Taylorian ones - limited those possibilities.

ICTs have accelerated these changes and facilitated access to new training methods not available on the traditional circuit. Online training courses such as the so-called massive open online courses or MOOCs are a great success, thanks in particular to their ease of access and the fact that they are free of charge. In France, the personal training accounts (compte personnel de formation/CPF) introduced by 
the Vocational Training Act of $5^{\text {th }}$ March 2014 (and confirmed by legislation due to come into force in the summer of 2018) have accentuated this phenomenon, with more and more qualifications being awarded on completion of these training programmes and making these skills more visible to the public. Indeed, the digital sector is today one of the most active in registering qualifications in the inventory.

\section{The Importance and Standardization of the Use of Internal Trainers}

Given the central role of novelty and innovation in their production and processes, digital companies pay particular attention to collective practices for the transmission and sharing of skills. As Livian stated in 2000, "it is a question of reintegrating into the normal functioning of the organization the practical skills that they had previously deployed clandestinely". Standardizing the use of internal trainers is a marker of practices that are in line with this objective. Thus more than two thirds of the innovative digital companies use internal trainers (compared to one third of their non-innovative counterparts) in order to give the less experienced the benefit of their colleagues' skills and to help them develop more quickly.

Tutoring is widely developed within these companies, both formally ( $72 \%$ of the companies concerned vs. $50 \%$ of the non-innovative) and informally ( $82 \%$ vs. $77 \%$ ). In a broad sense, internal trainers are "workers caught within socioeconomic issues of viability, of quality, of the performance levels of the training tools that they design, coordinate and/or facilitate" (Boccara and Delgoulet, 2015).

In the innovative digital companies, $41 \%$ of trainers or tutors are selected from among the most highly qualified employees (compared to $29 \%$ in the noninnovative companies). On the one hand, it shows once again the importance these companies attribute to excellence. On the other hand, it reflects the availability for these tasks of the most "experienced" employees, who are aware that tutoring not only fulfils the objectives of knowledge transmission but also fosters exchanges and therefore the development of skills. Thus new employees recruited directly after their initial training find themselves in conditions very conducive to integration. To this extent, tutoring practices reinforce the conclusions of the previous section on the integration of young recruits.

This way of working enables employees to get to know each other's activities better and to create links between the different work stations (Daneshgari and Moore, 2016). Thus almost all the employees working in an innovative digital company declare that their work enables them to learn new things. 57\% says that at least one of their colleagues teach them to do part of their job, especially in SMEs. Indeed, these employees are eager to learn: nearly two thirds of them say they lack certain skills (compared to 55\% of the employees working in the noninnovative companies). Moreover, $44 \%$ also declare that they are often required to teach at least one of their colleagues to do part of their job. This culture of learning together strengthens the culture of producing together and is therefore part of the mechanism of innovation through the exchange of knowledge. 


\section{Conclusions}

The digital sector is characterized by a rapid growth and evolving market characterised by technology advancement where the adaptation of companies is mainly linked to their ability to innovate. Firstly, the balance between acquiring the high standards of excellence while recruiting, the conversion from academic to tacit knowledge, the transfer to the collective is consistent with the resource-based approach. Secondly, the study of training reveals that companies have adopted a strategy for knowledge generation based on a social structure included in the organization of human resources. The use of internal trainers and the inclusion of internal training functions within job descriptions highlights the fact that learning management is at the very core of human resources policy (Dubois and Rousset, 2017).

The methods of acquiring and sharing skills may be a means of strengthening the culture of innovative digital companies and so a starting point for analysing the role human resources play in the strengthening of corporate practices. This is not a simple issue, since a company's culture cannot be reduced to a single indicator but is determined rather by the coherence between several indicators. The link between recruitment and training, the coherence between the forms of training formal, non-formal or informal - and the identity of the various occupations and work groups around the sharing of skills are the main elements that validate our hypothesis that the culture of innovative digital companies is built around knowledge management. Digital companies are therefore similar to capabilityfriendly firms which offer employees favourable conditions enabling them to be proactive in the design of their career paths, and reconcile training oriented toward companies' competitiveness with equal access to training and equal freedom for employees to actually engage with it (Lambert et al., 2012).

These initial results could be extended to subsequent research. A further stage in the analysis would be to undertake an additional qualitative study in order better to account for the impact of the innovation dimension in employees' career development. In particular, this kind of study would account for the difference between a company's internal work space and an employee's social space, which frequently extends beyond the boundaries of a company operating in an ecosystem built on networks.

\section{References}

Banker, R. D., Bardhan, I., Asdemir, O., 2006. Understanding the Impact of Collaboration Software on Product Design and Development, Information Systems Research, 17(4) p. 352-373. DOI: https://doi.org/10.1287/isre.1060.0104.

Barney, J. B., Clark, D. N., 2007. Resource-based Theory: creating and sustaining competitive advantage, New York: Oxford University Press. DOI: https://doi.org/10. 1002/pa.303.

Boccara, V., Delgoulet, C., 2015. Works analysis in training design: How ergonomics helps to orientate upstream design of virtual training environments, Activités, 12(2), 137-158. DOI: https://doi.org/10.4000/activites.1109. 
Boisot, M. H., 1998. Knowledge Assets: Securing Competitive advantage in the knowledge economy, Oxford University Press, New York.

Cave, R. E., 2000. Creative industries: Contracts between art and commerce, Harvard University Press.

CIGREF, 2014. L'entreprise 2020 à l'heure numérique, enjeux et défis, Réseau des grandes entreprises [The 2020 Company in the Digital Age, Issues and Challenges, Large companies' Network]. Club informatique des grandes entreprises françaises, Octobre. https://bit.ly/2Sq0yj6.

Coad, A., Rao, R., 2008. Innovation and firm growth in high-tech sectors: A quantile regression approach, Research Policy, 37, p. 633-648. DOI: https://doi.org/10.1016/ j.respol.2008.01.003.

Cordelier, C., 2011. Innovations et performances des sociétés: comparaison entre les services et l'industrie manufacturière [Innovations and performance of companies: comparison between services and manufacturing industry]. Direction Générale de la Compétitivité de l'Industrie et des Services (DGCIS), chapitre sur l'innovation and la performance économique.

Daneshgari, P., Moore, H., 2016. Organizational transformation through improved employee engagement - "How to use effective methodologies to improve business productivity and expand market share", Strategic HR Review, Vol. 15 Issue: 2, p.5764. DOI: https://doi.org/10.1108/SHR-02-2016-0007.

De Meyer, A., 1991. Tech talk: How managers are stimulating global R\&D communication, Sloan Management Review (Spring 1991), 49-58.

Deltour, F., Lethiais, V., 2014. L'innovation en PME et son accompagnement par les TIC: quels effets sur la performance? [Innovation in SMEs and its support through ICT: what effects on performance]. Systèmes d'Information et Management, 19(2), p. 4472.

Devriès, V., Lê, J., 2015. Un tiers des entreprises de 10 salariés ou plus n'utilisent pas les fonds dédiés à la formation [One third of companies with 10 or more employees do not use the funds dedicated to training]. DARES analyses $n^{\circ} 31$, Avril.

Doran, J., Jordan, D., O'leary, E., 2012. The effects of the frequency of spatially proximate and interactions on innovation by Irish SMEs, Entrepreneurship and Regional Development, 24(7-8), 705-727. DOI: https://bit.ly/2yHv0Nk.

Dubois, J. M., Marion-Vernoux, I., Noack, E., 2016, The training and employee trajectory surveys: a new look at in-firm training, Céreq, training and employment $n^{\circ} 121$, January-February.

Dubois, J. M., Rousset, P., 2017. Adapting skills: a challenge digital companies have to meet, Céreq, training and employment $n^{\circ} 131$, December.

Conseil d'Orientation pour l'emploi, 2017. Automatisation, numérisation et emploi: Tome 2: l'impact sur les compétences [Automation, digitization and employment: Volume 2: The impact on skills]. Report, Septembre. https://bit.ly/2ESN78D.

European Commission, 2014. E-skills for job in Europe, Country report, France, January. https://bit.ly/2Srpoz9.

Fournier, C., Lambert, M., Marion-Vernoux, I., 2017. Apprentissages informels et 'dynamique de travail' [Informal learning and 'work dynamics']. Sociologies pratiques 2017/2 (n`35), p. 73-81. DOI: https://doi.org/10.3917/sopr.035.0073.

Gallouj, F., 2002. Innovation in services and the attendant old and new myths, Journal of Socio-Economics, 31, p. 137-154.

Gertler, M. S., Wolfe, D. A., Garkut, D., 2000. No place like home? The embeddedness of innovation in a regional economy, Review of international political economy, 7(4), 688-718. DOI: https://bit.ly/2AxC00w. 
Ghoshal, S., Arnzen, B., Brownfield, S., 1992. A learning alliance between business and business schools: executive education as a platform for Partnership, California Management Review, Vol. 35, issue 1, p. 50-67.

Kogut, B., Zander, U., 1992. Knowledge of the firm, combinative capabilities, and the replication of technology, Organization Science, 3(3), 383-397. DOI: https://doi.org/ 10.1287/orsc.3.3.383.

Kraimer, M. L., Seibert, S. E., Wayne, S. J., Liden, R. C. and Bravo, J., 2011. Antecedents and outcomes of organizational support for development: the critical role of career opportunities, Journal of Applied Psychology, 96, 3, 485-500. DOI: https://doi.org/ 10.1037/a0021452.

Lambert, M., Vero, J., Zimmermann, B., 2012. Vocational training and professional development: a capability perspective, International Journal of Training and Development 16:3, p. 164-182. DOI: https://doi.org/10.1111/j.1468-2419.2012. 00402.x.

Livian, Y., 2000. Organisation: théories et pratiques [Organization: theories and practices]. Editions Dunod.

Mettling, B., 2015. Transformation numérique et vie au travail [Digital transformation and work life]. Rapport destiné au Ministre du Travail, de l'Emploi et de la Formation Professionnelle, Septembre. https://bit.ly/1OyAmw8.

Ministry de l'Economie et des Finances, 2016. Les besoins et l'offre de formation aux métiers du numérique [The needs and training offer for digital professions]. Rapport interministériel, Février. https://bit.ly/2OT8knw.

Mongo, M., 2013. Les déterminants de l'innovation : une analyse comparative service/ industrie à partir des formes d'innovation développées [The determinants of innovation: a comparative service/industry analysis based on the forms of innovation]. Revue d'économie industrielle, 143, p. 71-108. DOI: https://doi.org/10. 4000/rei.5632.

Nelson, R., Winter, S., 1982. An evolutionary theory of economic change, Harvard University Press, Cambridge, MA.

Nonaka, I., Von Krogh, G., 2009. Tacit knowledge and knowledge conversion: controversy and advancement in organizational knowledge creation theory, Perspective, Organization Science 20(3), p. 635-652. DOI: https://doi.org/10.1287/orsc.1080.04 12.

OPIIEC, 2017. Emploi-formation, tendances $1^{\mathrm{er}}$ semestre 2017 [Employment-training, trends $1^{\text {st }}$ half of 2017]. Note $n^{\circ} 3$, Observatoire Dynamique des métiers du Numérique, de l'Ingénierie, des études \& Conseil et de l'événement, Septembre. http://observatoire-metiers.opiiec.fr/telecharger/notes/2017-09.pdf.

Pavlou, P. A., El Sawy, O. A., 2006. From IT leveraging competence to competitive advantage in turbulent environments: The case of new product development, Information Systems Research, 17(3), p. 198-227. DOI: https://doi.org/10.1287/isre. 1060.0094 .

Petrariu, I. R., Bumbac, R., Ciobanu, R., 2013. Innovation: a path to competitiveness and economic growth. The case of CEE studies, Theoretical and Applied Economics, Volume XX (2013), No. 5(582), p. 15-26.

Rogers, M., 2004. Networks, firm size and innovation, Small Business Economics, 22, 141-153.

Spender, J. C., Grant, R. M., 1996. Knowledge and the firm: Overview, Strategic Management Journal 17 (Winter) 45-62. DOI: https://bit.ly/2Axy688.

Schaffer, V., Matt, M., 2016. Development of academic entrepreneurship in a non-mature context: the role of the university as a hub-organisation, Entrepreneurship \& Regional Development, 28(9-10), 724-745. DOI: https://bit.ly/2qgkZCp. 
Simon, L., 2009. Underground, upperground, middleground: les collectifs créatifs et la capacité creative de la ville [Underground, upperground, middleground: creative collectives and the creative capacity of the city]. Management international. DOI: https://doi.org/10.7202/037503ar.

Teece, D. J., 1998. Capturing value from knowledge assets: The new economy, markets for know-how, and intangible assets, California Management Rev. 40(3) 55-79. DOI: https://doi.org/10.2307/41165943.

Van Der Heijden, B. I. J. M., 2003. Organizational influences upon the development of occupation expertise throughout the career, International Journal of Training and Development, University Press, Oxford, UK. DOI: https://doi.org/10.1111/14682419.00178. 
